\title{
La dicotomía turista / viajero en De Madrid a Nápoles (1861) de Pedro Antonio de Alarcón
}

\author{
Jordi Canals \\ Università degli Studi di Trento (Italia)
}

\begin{abstract}
Resumen: Pedro Antonio de Alarcón, autor de la crónica de viajes que lleva por título De Madrid a Nápoles (1861), se presenta a sí mismo en sus páginas como un observador crítico del incipiente fenómeno del turismo organizado, en torno al cual disemina en el texto numerosas observaciones. Alarcón enjuicia también de modo negativo los nuevos auxilios editoriales que, tales como la guía turística, cuentan con el favor creciente de los viajeros de mediados del siglo XIX. Desde un punto de vista formal, la obra se presenta como una hibridación de géneros que une estrategias redaccionales que derivan de la innovadora crónica periodística, clichés formales propios de la narrativa tradicional de viajes (básicamente las que entroncan con el diario y el epistolario), coexistiendo todo ello con abundantes notas en estado bruto del viajero que va dejando constancia periódica de sus impresiones en su diario personal.
\end{abstract}

Palabras clave: literatura de viajes, turista, viajero, guías turísticas

Title: Tourist / traveller dichotomy in Pedro Antonio de Alarcón’s De Madrid a Nápoles (1861)

Abstract: Pedro Antonio de Alarcón, the author of the book entitled From Madrid to Naples (1861), appears in its pages as a critical observer of the emerging phenomenon of organized tourism, around which he makes numerous remarks in his work. Even new editorial tools, such as tourist guides that were increasingly used by travelers in the mid-nineteenth century, are considered by Alarcón in a negative way. From a formal point of view, Alarcón's book is a hybridisation of genres that summons innovative journalistic writing skills, literary patterns already experienced in classical travel writing (concerned mainly with diary and epistolary genres) and a great deal of sketches taken d'après nature by the traveler and kept in his notebook.

Keywords: travel writing, tourist, traveler, tourist guide

i E-mail: jordi.canals@lett.unitn.it 


\section{Introducción}

En la literatura contemporánea que gravita en torno al fenómeno cultural del viaje es constante el intento de los autores occidentales de tomar distancias respecto al estereotipo del turista, entendido este como "el producto y el cliente de estructuras comerciales que administran el viaje de ocio de acuerdo con las exigencias de las empresas comerciales y su burocracia" (Pera, 1998: 509). La singularidad de la experiencia del viajero, que privilegia metas insólitas, aunque no necesariamente lejanas en el espacio, y que afronta dicho reto como un hito en el desarrollo formativo del individuo, se contrapone a la actitud homologada de la masa de turistas que se desplaza de modo planificado a destinos turísticos impuestos por modas que obedecen a ritos sociales y condicionamientos de carácter económico.

Ha calado hondo tal distinción, hasta el punto de que los estudiosos del lenguaje del turismo han advertido en las publicaciones especializadas en el sector de los viajes la tendencia editorial al reemplazo generalizado del sustantivo turista, lo que comporta por parte de periodistas y redactores la búsqueda de alternativas léxicas menos marcadas. Limitándose al análisis de medios españoles, Maria Vittoria Calvi (2000) ha puesto de relieve

la tendenza a sostituire il termine [turista] con altri vicini che si distinguano dall'immagine più stereotipata. Si osserva ad esempio una netta prevalenza del termine viajero, di significato più ampio ("colui che viaggia") rispetto a turista, ma che soprattutto richiama modalità di turismo meno standardizzate e più orientate alla ricerca personale: come abbiamo visto, la condizione di viaggiatore viene contrapposta a quella di turista, e rivendicata da scrittori e intellettuali (2000: 62).

Es esta una actitud editorial que refleja el tan extendido rechazo al turista, que se configura como objetivo predilecto de la censura promovida por sectores intelectuales, tal como apunta Dean MacCannell (2005: 13), uno de los padres fundadores de la sociología científica del turismo. Con él se alinea Hans Magnus Enzensberger, para quien el turista se ha convertido en una de las figuras sociales más condenadas y caricaturizadas por la cultura de nuestro tiempo (1998: 27).

El sustantivo español turista deriva del inglés tourist que, a su vez, se remonta al postverbal francés tour (vid. $D C E C H$, s.v. torno). De la palabra homónima inglesa, que denota 'viaje' (y ya no, como en francés, 'vuelta, paseo'), se formaron por derivación tanto el sustantivo tourism como tourist. Se ha documentado por vez primera el sustantivo inglés tourist en Remarks Made in a Tour from London to the Lakes of Westmoreland and Cumberland (1792), texto en el que Adam Walker, al describir el tramo de sendero que de Patterdale lleva a Keswick, teme que el silencio del paraje y la armonía social de los lugares que atraviesa puedan quedar alterados al paso del turista ruidoso:
"Solitude and peace reign here undisturbed, except by the rattling tourist, who excites envy and false ideas of happiness among the peaceful inhabitants" (Walker, 1792: 82) ${ }^{1}$.

Numerosos son los testimonios hispanos de la entrada de dicho anglicismo en nuestra lengua a lo largo del s. $\mathrm{XIX}^{2}$, por más que la RAE no recoja la voz turista en el diccionario académico sino hasta su edición $14^{\mathrm{a}}$ (1914), donde la define s.v. como "Viajero que recorre un país por distracción y recreo". La necesidad de ir en busca de entretenimiento en los períodos de ocio y el placer que deriva de tales escapadas, ha sido para los académicos de la RAE el rasgo distintivo que caracteriza al desplazamiento turístico y que presupone, por contraste, la existencia de otros muchos individuos pertenecientes a nuestra sociedad que se desplazan movidos por intereses heterogéneos, pero en ningún caso por el gusto de afrontar la experiencia viajera. Desde su primera entrada, tal consideración persistirá en el conjunto de ediciones del diccionario de la RAE hasta llegar a la $22^{a}$ (2001), la más reciente hasta la fecha, y en la que sigue definiéndose el turismo como la "Actividad o hecho de viajar por placer" y turista sencillamente la "Persona que hace turismo".

Contraponemos esta visión académica, en exceso reductiva, a la definición que proporciona la Organización Mundial del Turismo (WTO/OMT), la cual nos da indicios de la actitud sincrética con la que hoy en día se valora el difundido fenómeno social del turismo, que se interpreta como el

conjunto de actividades que realizan las personas durante sus viajes y estancias en lugares distintos al de su entorno habitual, por un período de tiempo consecutivo inferior a un año, con fines de ocio, por negocio o por otros motivos, y no por motivos lucrativos (cit. en Calvi, 2006: 14).

Bastaría con dar un vistazo a la actitud con la que algunos autores contemporáneos, pertenecientes a distintas tradiciones culturales, se aproximan al fenómeno del viaje para caer en la cuenta de que en nuestra época se ha problematizado la dicotomía turista / viajero hasta cargar, desde un punto de vista semántico, estos términos con muy otros significados. Es por lo demás un binomio que, como hemos mencionado, percibimos con acusado carácter antitético, si bien en tal distinción no entra necesariamente en juego el factor hedonístico que se supone comparten ambas categorías de individuos. El rasgo distintivo cabe buscarlo, en todo caso, en la mayor o menor empatía que estos muestran en su respectivo desplazamiento por el espacio: "turista - ha escrito Julio Llamazares - es el que viaja por capricho y viajero el que lo hace por pasión" (1998: 22). El primero sacia pronto el deseo de evasión con su deambular casual, mientras que el viajero lleva a cabo su acción por una determinada geografía a la que queda ligado de modo tan íntimo que el viaje acaba convirtiéndose incluso en acto introspectivo. Y es que para el escritor leonés cuenta poco la distancia que se recorre y mucho, en cambio, el fardo de referencias culturales y autobiográ- 
ficas con el que se adentra en el microcosmos familiar, ya sea este el Valle del río Curueño, en el que se compendia gran parte de la geografía de su infancia, como la región portuguesa de Trás-os-Montes, tan desconocida pese a estar tan al alcance de su mano. La de Llamazares es una sintética definición que armoniza con la sublimación del viaje 'doméstico', aquel que se efectúa al llevar a cabo una incursión en nuestro pequeño mundo y que, en opinión de Claudio Magris, constituye la aventura que mayor riesgo comporta para el viajero:

il viaggio più affascinante è un ritorno, un'odissea, e i luoghi del percorso consueto, i microcosmi quotidiani, attraversati da tanti anni, sono una sfida ulissiaca (2005: XXI).

Se desprenden de estas líneas los motivos que caracterizan algunos de los rasgos distintivos del viaje: la conciencia del peligro inherente al viaje que se lleva a cabo con total implicación por parte del individuo; el retorno aventurero que tiene por referencialidad libresca la navegación de Ulises a Ítaca; la fascinación por todo aquel desplazamiento en el espacio, y en el fondo también en el tiempo, que entraña un desafío. Aunque la intención resulta en apariencia contradictoria, es completa la sintonía de las palabras de Magris con las de Paul Bowles, el novelista norteamericano que en las páginas iniciales de The Sheltering Sky (1949) incluye una larga disquisición en la que se interroga en torno a la esencia del viaje $\mathrm{y}$, convirtiéndose en intérprete de cuanto medita uno de los personajes protagonistas recién desembarcado en un puerto del norte de África, escribe lo siguiente:

He did not think of himself as a tourist; he was a traveler. The difference is partly one of time, he would explain. Whereas the tourist generally hurries back home at the end of a few weeks or months, the traveler, belonging no more to one place than to the next, moves slowly, over periods of years, from one part of the earth to another (2002: 6).

Tarde o temprano el turista pondrá un día término a su viaje, mientras que para el viajero no existirá jamás, en definitiva, la seguridad de un regreso a casa. En el fragmento se perfila la imagen del viaje lineal, antítesis del viaje circular, en el que la trayectoria existencial del viajero se proyecta hacia el infinito: "Il viaggio deviene allora un cammino senza ritorno, alla scoperta che non c'è, non può e non debe esserci retorno" (Magris, 2005: XII).

$\mathrm{El}$ autor de libros y reportajes de viajero vende a menudo al lector la ilusión de que se halla por encima del turista y ello por más que sea consciente de que terminará cayendo en parecidas trampas, como en el caso paradójico de los autores modernistas de América Latina asentados en Europa desde fines del siglo XIX (Pera, 1998: 513-514). Goza el viajero de una superioridad moral que estriba en cualidades excepcionales que lo distinguen de la masa homologada de turistas y de su insaciable "voracidad vi- sual", de acuerdo con una célebre observación barojiana (Arbillaga, 2005: 433). Así, por ejemplo, en la capacidad para poder enfrentarse a la realidad con una sensibilidad distinta a la del turista o en su facilidad para dar con los rincones secretos a los que otros difícilmente podrían llegar. El viajero es también el individuo capaz de percibir lo trascendente en episodios aparentemente nimios de la vida cotidiana de los lugares por los que pasa: estampas que revisten importancia y a las que presta atención hasta el punto de que no olvida dejar constancia pormenorizada de ellas en sus cuadernos de viaje, sin dejarse cegar en cambio por los grandes iconos de atractivo monumental que le puedan salir al encuentro y que suscitan el rito de la sacralización colectiva por parte de la masa de turistas. El viajero es un ser dotado de sensibilidad superior, capaz de reparar en lo que pasará desapercibido al turista, al que el periodista argentino Lucio Vicente López así caricaturiza en sus Recuerdos de viaje (1881):

Ya veo la cara de un turista burgués, que ha regresado a Buenos Aires, contando la hazaña de haber trepado hasta el último peldaño de la cúpula del Panteón, ávido de una descripción catalogada o inventariada, contrariarse con una página cuyos actos principales son los pájaros, y meditar en la diferencia que existe entre ver estos personajes humildes, y la muy erudita de contar los pies de altura de la columna Vendôme. Por ahí no más, queriéndose salir de los puntos de la pluma, anda alguno de estos entes seráficos, que espulgan a Bædeker como si bebieran la crónica de lo desconocido en un papiro egipcio; echémosle a un lado para que la malicia no lo descubra, y volvamos a nuestros pájaros (López, 1915: 149).

En el fragmento se satiriza al nuevo rico adinerado que afronta el viaje como rasgo de distinción, que acata las prescripciones de la guía, de la que nunca se separa en el transcurso de su viaje, y que viaja con la convicción de que tal experiencia le será útil para adquirir de manera natural la erudición indispensable con la que poder desenvolverse, al regreso a casa, en los círculos en los que aspira a poder integrarse en calidad de experimentado hombre de mundo.

Llevaremos a cabo, acto seguido, una aproximación a la literatura de viajes de Pedro Antonio de Alarcón, pionero en la España decimonónica de este renovado género editorial sensible a las transformaciones sociales y culturales. Juzgamos que constituye un testimonio clave para comprender la visión con la que el intelectual decimonónico enjuicia de manera crítica el turismo organizado que a mediados del s. XIX constituye un fenómeno consolidado.

\section{Alarcón y la literatura de viajes}

Pedro Antonio de Alarcón (1833-1891) alcanzó notoriedad de reportero durante la campaña de África, el primer conflicto bélico en el que los mandos castrenses españoles se valieron de estrategias mediáticas de manera delibera- 
da. En 1859 sentó plaza el guadijeño como voluntario en las tropas españolas que, en su avance hacia Tetuán, combatieron al ejército del Sultán marroquí. Aprovechando su posición privilegiada en la primera línea del frente, redactó crónicas periodísticas en las que daba cuenta de los éxitos de la expedición militar bajo el mando supremo del general Leopoldo O'Donnell. Dado el interés con que los lectores españoles siguieron sus artículos, el mencionado material periodístico se recogió más tarde en el volumen Diario de un testigo de la guerra de África (1859), que cosechó de inmediato gran fortuna editorial ${ }^{3}$.

El prólogo, que al mismo tiempo constituye una dedicatoria de la obra al general Antonio Ros de Olano, lleva la fecha del 2 de diciembre de 1859, cuando aún había de llegar la victoria de Wad-Ras tras la cual se entablaron las negociaciones de paz que concluirían con el Tratado de Tetuán. En estas páginas preliminares, el cronista-soldado anticipa a los lectores de su obra que en ella se propone recoger "el diario de mis impresiones y pensamientos durante la guerra; la crónica de lo que vea y medite; la descripción de los lugares que recorra y de los acontecimientos a que asista" (Alarcón, 2005: IV). Pasa a un segundo plano el objetivo de facilitar las claves de un conflicto que propicia un clima de fervor patriótico, mientras que el autor admite en cambio querer "hacer viajar conmigo al que me lea" (2005: IV). Es esta toda una declaración de principios que encaja con los acostumbrados propósitos de quien desde antaño decide poner por escrito la propia experiencia nómada.

José F. Montesinos ha definido a Alarcón como "un hombre de ojos" (1977: 17), poniendo de relieve una cualidad que ha favorecido su talento para la descripción ${ }^{4}$. Es este un rasgo con el que concuerda Juan Luis Alborg, que destaca en Alarcón el hecho de que "poseía una poderosa retina de pintor particularmente dotada para captar el detalle plástico y apresar el rasgo lleno de vida y movimiento" (1996: 513). Lo demostrará el escritor andaluz también en la obra sucesiva: De Madrid a Nápoles (1861), que Pardo Bazán define como el resultado literario de "un viaje en toda regla" (Pardo Bazán, [s.a.]: 37). Fue este texto, a su vez, el resultado de un Viaje de recreo, realizado durante la guerra de 1860 y sitio de Gaeta en 1861, como se lee en el subtítulo. Tendrá de nuevo trasfondo bélico, si bien en esta ocasión Alarcón no queda implicado en la guerra por la unificación italiana más que como espectador distanciado de los hechos, sin ir deliberadamente en su busca, tal como admite en el prólogo:

Creo que el que busca los hechos casi nunca los halla, y que es mejor pararse en una esquina y aguardar a que pasen delante de uno. Todo el que penetra en las cosas, las violenta y desnaturaliza. Yo prefiero dejarlas manifestarse espontáneamente (1861: IX).

Con frecuencia los viajeros decimonónicos no eligen el itinerario más razonable y directo para llegar a destino, sino que acaban optando por la distancia más larga entre dos puntos. El caso de Alarcón no es excepcional: la deci- sión de viajar a Italia en compañía de Charles Yriarte le lleva a Ginebra, luego al valle de Chamonix movido por la curiosidad de contemplar el Mont Blanc y, remontando su andadura, al Cantón de Valais para entrar de ese modo, tras superar el Puerto del Simplón, en aquella Italia ya libre de la tiranía de los austríacos. Alarcón es tan solo el primero de una serie de escritores españoles que se aproximarán a Italia, ese "volcán que revienta" como lo define en su prólogo (1861: VIII), acuciados por el interés de documentar el proceso de unificación del nuevo Estado que está surgiendo al sur de los Alpes ${ }^{5}$.

Alarcón no abandonará en el futuro el gusto por la narrativa de viajes, si bien en ninguna de las obras sucesivas que cabe adscribir a dicho género - La Alpujarra (1874), Mis viajes por España (1883) y Más viajes por España (1891) - mostrará parecida ambición periodística por dejar constancia escrita de la fugacidad de sucesos que configuran la historia inmediata.

\section{Un viaje de indagación social}

El Capt. 1 de De Madrid a Nápoles se enmarca en Francia, cuya visita por parte de Alarcón se configura como una incursión hacia el futuro. Explicitamente define aquella estancia como "un viaje al porvenir de nuestro pueblo" (1861: VIII), siendo París el modelo al que aspira la sociedad española decimonónica. Había viajado a la capital por vez primera en 1855 , desde donde envió crónicas destinadas al periódico madrileño El Occidente dando noticia sobre la Exposición Universal que se celebró aquel año (Pardo Canalís, 1991: 8-9); pero un lustro más tarde, el choque del escritor andaluz con aquella realidad fue traumático: el Alarcón tradicionalista, opuesto a la sociedad industrial y defensor de valores conservadores, se fragua tal vez en este contacto fallido con el progreso y la civilización moderna, con el París que se erige en emblema de la civilización moderna y de la modernidad que Alarcón teme que se imponga como modelo social en todo Occidente (López, 2008: 174-179).

El tradicionalismo del escritor de Guadix poco sintoniza a su vez con la Roma pontificia a cuya agonía asistirá al término de su viaje y de la que queda igualmente desencantado. Tal rechazo lo subraya todavía más al contraponer la postración en la que ve sumidos a quienes sufren todavía la administración de los Estados de la Iglesia, con la exaltación de los italianos libres, de la que ha sido testigo al recorrer los territorios bajo la tutela de los Saboya antes de poner pie en territorio papal. Entre ambos extremos, París y Roma, el autor se muestra confusamente equidistante:

Sepamos quien tiene razón; si París o Roma; si los dos, o si ninguno. Estudiemos los inconvenientes del Imperio y los del Papado. Comparemos las iniquidades de la libertad y las de la tiranía. Veamos dónde está más degradada la humanidad, si bajo el yugo de un positivismo grosero o bajo el yugo de un fanatismo irracional (Alarcón, 1861: VIII). 
En estas líneas del prólogo se encierra el objetivo declarado de un viaje que nada tiene de recreo (desmintiendo el largo subtítulo de la obra) y que se configura, en cambio, como vía directa al conocimiento de un modelo de sociedad que avanza imparable, frente a una anacrónica teocracia secular que agoniza en el corazón del Mediterráneo.

Aunque el relato de viaje de Alarcón parece apuntar a una tesis de naturaleza ideológica, su autor muestra cautela llegada la hora de manifestar abiertamente las propias convicciones. Actúa de manera deliberada, incitando a que sea el lector quien saque las debidas conclusiones tras la lectura de sus notas de viaje. Quiere hacerlo partícipe de su experiencia y evitarle, en cambio, el condicionamiento de un punto de vista interpretativo que ha sumido en el desconcierto al mismo Alarcón (1861):

haré que me acompañéis en mi viaje; os daré mis impresiones con preferencia a mis raciocinios; recorreréis conmigo la Italia y la Francia; veréis lo que yo he visto; oiréis lo que yo he oído; me seguiréis a todas horas; os pasará lo que a mí me ha pasado; sentiréis indudablemente las indignaciones, las alegrías y las tristezas que yo he sentido, y de esta manera, al final de nuestra peregrinación, tendréis las ideas que yo tengo y podréis, si se os antoja, publicar la obra dogmática, el folleto político o el ensayo filosófico que yo no me atrevo a escribir hoy (1861: IX).

De Madrid a Nápoles, que constituye un espejo de cuanto ve a su paso el autor y es compendio de una realidad heterogénea, se impone como instrumento auxiliar que hace posible que el lector viaje de modo virtual. Alarcón no busca agradar a los lectores por sus méritos descriptivos, sino que le basta con que se embelesen ante la realidad que ha quedado plasmada en las páginas de su obra: "quiero que viajen, no que me lean; que miren, no que me oigan; no les presento una pintura, sino un espejo; no les ofrezco una copia de los objetos, sino un lente para que los vean por sus propios ojos" (1861: 206).

\section{En busca de un formato textual}

En las páginas introductivas de los textos a los que nos hemos aproximado se hace explícito en ambos el deseo insistente, por parte de Alarcón, de que el lector lo 'acompañe' en su viaje. El autor experimenta con distintas estrategias redaccionales con el objetivo de hacer revivir la emoción de su experiencia al interlocutor pasivo que toma el libro entre sus manos.

La más destacable constituye el trasvase al texto de las hojas de su cartera de viaje, "llenas de apuntes insustanciales, inconexos, acerca de mis aventuras propias" (Alarcón, 1861: IX). La obra final se configura en buena parte como un producto que surge de la sensación inmediata, de la que deja constancia el autor en sus notas escritas a lápiz en el libro de memorias que redacta en "los mismos sitios y en los mismos instantes a que hacen re- ferencia" (1861: 106 y 231). Es esta una idea sobre la que volverá en Historia de mis libros al evocar la técnica de escritura adoptada para De Madrid a Nápoles, destacando el hecho de que

fue redactado verdaderamente en los propios sitios o ante las propias obras de arte que menciona, y tanto es así, que aún conservo los álbumes de bolsillo en que fui apuntando con lápiz, muy extensamente, y d'aprés nature, los caracteres, rasgos fisonómicos y circunstancias accidentales de cada cosa, así como los arranques, exclamaciones o juicios de impresión que me inspiró a primera vista (Alarcón, 1943: 15).

Es por tanto un proceso que, de dar crédito a las palabras del autor, ha llevado a cabo sometiendo tales apuntes a una revisión muy superficial, limitándose a ofrecer a sus lectores la redacción en bruto: "El libro está por escribir. De este volumen a un libro hay la misma distancia que del mineral a la moneda" (Alarcón, 1861: X). Con ello trata de conservar la misma frescura y espontaneidad con la que se redactaron aquellas notas dispersas y heterogéneas que garabateó en el transcurso del viaje. Aunque cabe suponer que Alarcón sometió el texto a un proceso mínimo de reescritura antes de darlo como definitivo a la imprenta, son frecuentes los pasajes en los que intenta transmitir al lector la ilusión de tener entre sus manos la primicia de un raro work on progress, haciéndolo partícipe del proceso germinal de su escritura.

El proceso es, en realidad, más complejo. En la obra lista para la imprenta, que sin duda fue sometida a una intensa labor de revisión, se funden heterogéneos materiales textuales. Distinguimos, por una parte, los apuntes personales tomados al hilo del viaje y que, como se ha dicho, algunas veces se trasvasan directamente al texto; así, por ejemplo, aquellos en los que describe los sentimientos que le asaltan al contemplar la caída de la noche sobre el Mont Blanc, la víspera de abandonar Chamonix ${ }^{6}$. A estas notas tomadas en la inmediatez de los hechos, se agregan otros materiales, muchos de los cuales introducen voces distintas en el texto: incorporación de textos literarios de otros autores - la navegación por el Lago de Ginebra favorece, por ejemplo, la inclusión de largos fragmentos del Childe Harold's Pilgrimage de Lord Byron que Alarcón mismo traduce (1861: 95-96) -; la transcripción de pasajes de carácter enciclopédico que toma de la guía Bædeker que le acompaña en su viaje $\mathrm{e}^{7} \mathrm{y}$ que vierte al castellano - véase al respecto la larga descripción del fenómeno glaciar del que le urge dejar constancia tras la excursión por el Mar de Hielo del Mont Blanc (1861: 111-114) -; notas que derivan de textos especializados - así las noticias relativas a Arnaldo de Brescia que encontramos en nota a pie de página y que confiesa vagamente haber sacado de un "diccionario biográfico" (1861: 280) -. A la polifonía de su texto contribuye también la incorporación de otros muchos materiales que observa a lo largo de su viaje: la reproducción de un cartel que anuncia un espectáculo teatral (1861: 398), rótulos curiosos (1861: 438), graffitis que 
lee en las paredes de las calles por las que pasa y que transcribe en las páginas de su cuaderno de viaje antes de que los cancele el paso del tiempo (1861: 389, 400 y 401) e incluso las palabras que escucha al azar en sus paseos por las callejuelas de Venecia (1861: 307 y 328). Todo le resulta curioso y llamativo, digno de tener cabida en su obra, por lo que no duda en amalgamar estos materiales heterogéneos dando pie a una experimentación formal.

En algunas partes de su obra se ajusta a las formas convencionales propias del diario de viajero y llega a adoptar, en los últimos capítulos, las que son características del género epistolar. Ello ocurre a partir del Capt. $\mathrm{X}$, cuando Alarcón pone por escrito sus primeras impresiones romanas y se dirige a un impreciso "Inolvidable amigo" (1861: 514). En este recae parte de la responsabilidad de la redacción de la obra, pues el guadijeño recuerda que en víspera de partir para Italia: "[me exigiste] que te escribiese una carta diaria" (1861: 514). Ruega Alarcón al amigo que conserve las cartas que le ha estado enviando, pues estas le serán de ayuda cuando redacte el volumen (1861: 514). La identidad de este misterioso destinatario se aclara al rememorar una velada con amigos españoles en el Caffè Greco ${ }^{8}$.

también te recordaban a ti en el Café Greco, joh Germán Hernández, mi buen amigo, que pasaste allí tantos años, de codos en aquellas mesas, dejando fluctuar tu espíritu entre las ilusiones del arte y las melancólicas memorias de la patria; a ti, el idólatra de la belleza pagana, que no supiste abandonar a Roma sin hacer de una de sus hijas la compañera de tu existencia!... Allí te recordaban y allí te recordé, porque muchas veces me habías hablado de aquel ahumado templo, de tus ilusiones de artista! (1861: 557).

Los últimos dos capítulos de la obra, centrados respectivamente en las ciudades de Roma y de Nápoles, enmarcados temporalmente en las fechas del 22 de diciembre de 1860 y del 25 de enero de 1861, mantienen intacta la forma epistolar.

De Madrid a Nápoles es una obra en la que Alarcón experimenta, como acabamos de comprobar, con variados formatos textuales. Conviven en ella el diario, la epístola, los apuntes del natural tomados en el transcurso del viaje y las descripciones reelaboradas al regreso a casa. Combina tales materiales con la armonía de un collage en el que cada elemento se subordina a un efecto que deriva del conjunto, conservando al mismo tiempo sus características textuales peculiares. Consigue, de ese modo, una obra amena que presenta formas y ritmos descriptivos variados mediante un formato textual que no se alterará en la reescritura de la segunda edición, aparecida en $1878^{9}$.

\section{Una filosofía del viaje}

La mejora de las vías de comunicación, la expansión del ferrocarril, el nacimiento de una clase media con capacidad económica suficiente para poder ambicionar al enriquecimiento cultural y cosmopolita del que en el pasado reciente habían disfrutado de modo exclusivo los aristócratas del Grand Tour, el éxito de la compañía de Thomas Cook (ya consolidado a mediados de siglo) cuya creación fue decisiva para dar con un modelo empresarial que facilitara la coordinación de los muchos y heterogéneos elementos que entraban en juego en la industria turística ya desde sus inicios, la existencia de una red eficiente de establecimientos hoteleros, el nacimiento del género editorial de la guía (que alcanzó una gran difusión gracias a la calidad de las obras propuestas por Murray y Bædeker), son todos ellos factores que favorecieron el auge del turismo a lo largo del siglo XIX (Buzard, 1993: 47-79). Como tantos otros viajeros europeos del s. XIX, Alarcón observa con mezcla de curiosidad y de desdén a los turistas que encuentra en su viaje y a los que cataloga en todos los casos con el galicismo touriste (Alarcón, 1861: 109, 292, 475 y 566 ${ }^{10}$, pese a que, por lo general, se trata de ingleses con los que tropieza en los lugares más impensables.

La filosofía de viaje de Alarcón entra en conflicto con la de quienes se desplazan por el continente y que encuentra a lo largo de su periplo europeo. Alarcón rechaza la planificación y su viaje es el resultado de quien se mueve deliberadamente dejándose llevar por el azar, la casualidad y el hedonismo: "he rodado por las ciudades y los caminos a merced de mi capricho, en vez de supeditarme a un plan de observación, de estudio, o cuando menos de viaje" (1861: IX). Desdeña, en cambio, el itinerario turístico y todos aquellos elementos que restan sorpresa y maravilla a la exploración viajera (1861: 94), al tiempo que privilegia lo imprevisible, algo que hay que poner en relación con el pasaje de su prólogo que acabamos de citar. En este sentido destaca el placer que como viajero le produce el partir "a la buena de Dios" (1861: 97). Es una idea recurrente que trasluce en muchos otros lugares, como cuando recién llegado a Venecia evita el auxilio de quienes le ofrecen acompañarlo a un hotel cercano a un lugar célebre: "Yo no quería probar las delicias de Venecia por medio de terceros o corredores. Prefería buscar a la deidad por mí mismo, aun a riesgo de que, desdeñosa, me ocultase al principio su hermosura" (1861: 297).

El viaje es para el escritor guadijeño un instrumento de valor pedagógico. Alarcón e Yriarte, en compañía de Jusuff, pasean por las calles de Turín y observan atentamente detalles y comportamientos, con lo que, de ese modo, el lugar habla "a pesar suyo" (1861: 178). En este sentido, se configura como un observador deductivo: a partir de la observación, se adquieren unas certezas que "llevaréis eternamente en lo íntimo del espíritu" (1861: 178) y concluye que "Si algo enseñan los viajes es precisamente esto" (1861: 178). Es todo él un fragmento muy interesante, pues incluye una larga lista de elementos que son los que han llamado la atención del viajero en su paseo por la turinesa Via Po, que se transmuta, de acuerdo con su definición metafórica, en un "cosmorama" (1861: 179). Del gusto por la observación de los detalles, de las "menudas circunstancias", escribirá por extenso el autor 
al dar noticias de su estancia romana (1861: 586).

Una vez en Ginebra, tras haber dejado atrás la aborrecida París, se produce el choque con la explotación turística del territorio y su consiguiente decepción: “QQué grato me hubiera sido venir a Suiza, cuando Suiza era bella sin saberlo; cuando aún no había hecho una mercancía de sus naturales encantos!" (1861: 94). Es una actitud que delata la nostalgia del autor por los tiempos en los que se corrían verdaderas aventuras de viaje y que lo emparenta, entre otros literatos viajeros, a Gérard de Nerval (Pera, 1998: 511-512). Esta predilección por la aventura y el riesgo le persuade a abandonar el territorio helvético tan pronto le resulte posible y escapar al encuentro de los recónditos parajes del Valle de Chamonix:

Yo no sentía ninguna gran curiosidad de recorrer todos aquellos puntos que las Guías y los ciceroni me describían como muy deliciosos. Estaban tan previstas y consignadas las emociones que se esperimentan en cada punto del lago; se ven en Ginebra tantos grabados y fotografías de sus más insignificantes parajes; érame tan notoria la historia de uno y otro lugar; había, en fin, tanto de rutinario y de normal en aquella escursión, hecha a gusto del capitán del vapor que lo llevase a uno, en compañía de otros cien touristes desconocidos, sin poder detenerse donde le agradara ni buscar a las cosas otro punto de vista que el prefijado por la costumbre, que preferí las espediciones en mulo que me aguardaban en medio de las nieves, solo, libre, entregado a mis contemplaciones y luchando a cada momento con accidentes imprevistos (1861: 94).

La previsibilidad de las expectativas de cuanto le deparará una meta geográfica al término de la etapa, unido al bagaje de las muchas impresiones y testimonios personales, que se han tejido en torno a ella y que el viajero lleva consigo, lo inmunizan y hacen que muestre insensibilidad frente a las excelencias del lugar ${ }^{11}$.

Queda constancia, en De Madrid a Nápoles, de los contactos esporádicos de Alarcón con los turistas. Son, a grandes rasgos, encuentros que suscitan su desaprobación, en los que les reprocha a menudo una conducta indecorosa. Así sucede en Isola Bella, donde las "touristes inglesas" (1861: 154) ${ }^{12}$ demuestran una elemental falta de respeto hacia los isleños al entrar con desenfado en la iglesia y examinar una a una sus capillas, sin importarles que se esté desarrollando en aquel momento una ceremonia religiosa. Es la misma actitud de repulsa que le suscita el hábito de los turistas británicos que, poco a poco, han ido cancelando la huella del paso de Napoleón por el palacio de la isla, arrancando la corteza del laurel monumental en que éste había dejado grabada la palabra Battaglia la víspera del combate de Marengo (1861: 155). Contempla asimismo con superioridad a quienes adquieren en Verona, "a peso de oro" (1861: 292), pequeños recuerdos alusivos al pretendido sarcófago de Julieta. De algún modo recela de estas presencias intrusas que transforman el lugar por el que pasan, hasta el punto de favorecer incluso una economía que explota los deseos de los mismos turistas. Eso no quita que el autor termine dejándose arrastrar por la corriente, incurriendo en tales actos de turista proclive al fetichismo e incluyéndose finalmente a sí mismo entre quienes cometen similares acciones censurables: "el [laurel junto a la Tumba de Virgilio] que hoy lo ha sustituido, plantado por Casimiro Delavigne, desaparecerá también, a causa de la costumbre que tienen o tenemos todos los viajeros de arrancarle una hoja cada vez que lo visitamos" (1861: 621).

Alarcón se hace eco de un ideal que la modernidad ha relanzado: la esperanza de que el paso del viajero no termine alterando el modo de vida del entorno que se atraviesa. Le disgusta el hecho de que la sociedad termine plegada a los deseos de los turistas o a su explotación, tal como advierte al llegar a la capital de la Toscana: "Florencia es un pueblo parásito que se nutre de los estranjeros. Yo creo que hay establecida en la Toscana una vasta asociación cuyo solo objeto es explotarlos" (1861: 487). En Verona, otro de los iconos del turismo internacional ya a mediados del s. XIX, Alarcón, tal como hemos apuntado, censura la banalización de la cultura que se doblega a una demanda masiva de los visitantes, burlándose sutilmente de las explicaciones del joven muchacho que muestra la supuesta sepultura de Julieta:

penetra en la vida pronunciando a todas horas y sin comprenderlas las dos palabras sacramentales de los humanos destinos, amor y muerte, sabe de memoria el argumento de la tragedia del inmortal Guillermo, y cuenta las cosas con tanto aplomo, inocencia, naturalidad y gracia, que hay momentos en que cree uno que Capulet, Montagu, Scalus, Baltasar, Mercutio y Gertrudis existen todavía; que Romeo, Julieta y Paris murieron hace dos o tres años, y que este chico se acuerda vagamente de ellos y de su trágico fin, como de una cosa que sucedió cerca de su cuna (1861: 292).

En las reacciones de Alarcón como viajero advertimos actitudes contradictorias, que Fernández Cifuentes ha llevado al extremo de tachar como falaces (1991: 16-17). Rechaza abiertamente el instrumento de la guía turística, que a mediados de s. XIX se ha erigido ya en símbolo de un nuevo modo de viajar, y toma distancias con respecto a este novedoso género editorial. Tal actitud equivale al rechazo a la estandarización del viaje que la guía impone a todos los viajeros que de ella se sirven, en lo que coincide con Enzensberger cuando advierte que el viaje se ha transformado en mercancía (1998: 40). No quiere ser confundido con un ramplón autor de guías: "yo no escribo la Guía de Turín, sino mis propias impresiones" (1861: 195). $\mathrm{Y}$, sin embargo, a menudo este género de textos se hallan presentes a lo largo de su viaje: "Caballero echaba entre tanto cuentas con una Guía en la mano y murmuraba gozosamente: -¡Pasado mañana en Roma!” (1861: 492). Es más, dicho auxilio bibliográfico llega a formar parte integrante de sus hábitos como viajero, hasta el punto de que, antes de adentrarse en la capital del Piamonte, hace 
que le traigan una guía y un plano, al tiempo que un conocedor de la ciudad le brinda una descripción primaria de corte enciclopédico que se funde con el texto (1861: 167168). Cae, por tanto, en la misma actitud contradictoria de Rubén Darío, que lucha por librarse del cliché y usos del turista sin lograr conseguirlo (Pera, 1998: 513).

\section{Conclusiones}

Al publicar De Madrid a Nápoles (1861) Pedro Antonio de Alarcón nos brinda un documento de notable interés para poder calibrar la visión crítica que un intelectual de mediados del s. XIX, avezado a los viajes, tenía del fenómeno de la incipiente industria turística. La valoración que lleva a cabo Alarcón es negativa, por cuanto advierte que está desapareciendo el modelo de viajero capaz de afrontar el riesgo y los imprevistos que, hasta pocas décadas antes, comportaba cualquier desplazamiento por el continente europeo. Lamenta que las metas geográficas de mayor belleza e interés estén sucumbiendo al turismo organizado de acuerdo con el modelo británico, restando de este modo valor a la experiencia del viaje, un acto que el escritor de Guadix concibe como exploración de un territorio y de una cultura ajena. Al mismo tiempo alerta sobre la modificación del entorno que la expansión del turismo está comportando.

De modo simultáneo, Alarcón alimenta desconfianza respecto a los instrumentos a los que está supeditado el turista. Sobre todo por lo que se refiere a la guía turística cuyo arquetipo Murray y Bædeker pusieron en circulación, ya en la primera mitad del s. XIX, con notable éxito editorial. El escritor guadijeño condena tales textos por su capacidad para allanar dificultades y crear expectativas, dificultando que sea el propio viajero quien ponga a prueba su talento para hacer frente a las adversidades del camino y sobre todo crear su propia vía al conocimiento geográfico y sociocultural. En este sentido cabe destacar el concepto de instrumento para la formación de la personalidad que el viaje reviste para Alarcón, el cual huye por lo demás del prejuicio y de las ideas preconcebidas de las que la guía turística se convierte en un temible instrumento de transmisión.

Pese a tales convicciones de principio, Alarcón no permanece inmune a la seducción de los productos que la industria editorial está creando, aquilatando y divulgando en aquellos mismos años con el objetivo de favorecer el disfrute turístico. A lo largo de su viaje echa mano repetidamente de la guía e incluso saca abundante partido de ella para la redacción de su propia obra. Desde este punto de vista, Alarcón presenta similitudes con numerosos escritores-viajeros contemporáneos que comparten con el andaluz el temor ante el avance arrollador de la industria turística y que, al mismo tiempo, sucumben a las comodidades y facilitaciones que esta propicia. Alarcón es el paradigma de quien evoca con nostalgia el viaje romántico (de cuya caducidad tiene plena conciencia) y se amolda a la modernidad y a las ventajas que brinda la sociedad industrial, por más que lo haga con desconfianza y lamentando que viejos estilos de vida hayan desaparecido de modo definitivo.

Como autor de libros de viajes, Alarcón no duda en experimentar con un formato textual nuevo. Manifiesta rechazo explícito a escribir una guía turística y busca en cambio la construcción de un texto en el que el lector quede atrapado, dándole la ilusión de estar acompañando al autor en su viaje. Al respecto, no ahorra estrategias redaccionales que aporten vivacidad a la descripción y verosimilitud al relato. Funde para ello formas tradicionales, como son el diario, el género epistolar o la presentación en bloque de datos enciclopédicos propios de las obras eruditas, con un texto innovador que deriva de la visión periodística de quien deja constancia escrita de encuentros ocasionales, conversaciones y estampas aparentemente nimias que permitan que el lector construya, partiendo de sus propias deducciones, un cuadro de aquella realidad que no conoce por experiencia personal, pero en la que ha logrado entrar de la mano del autor. Es Alarcón, desde este punto de vista, un precursor excepcional de la moderna narrativa de viajes.

\section{Bibliografía}

Alarcón, Pedro Antonio de

1861 De Madrid a Nápoles. Madrid: Impr. y Libr. de Gaspar y Roig.

Alarcón, Pedro Antonio de

1943 "Historia de mis libros". En Martínez Kleiser, Luis (Ed.), Obras completas (pp. 3-28). Madrid: Ediciones Fax.

Alarcón, Pedro Antonio de

2005 Diario de un testigo de la Guerra de África. Sevilla: Fundación José Manuel Lara.

Alborg, Juan Luis

1996 Historia de la literatura española. Madrid: Gredos. Arbillaga, Idoia

2005 Estética y teoría del libro de viaje: el viaje a Italia en España. Málaga: Universidad de Málaga.

Bowles, Paul

2002 The Sheltering Sky. Let it Come Down. The Spider's House. New York: The Library of America.

Buzard, James

1993 The Beaten Track. European Tourism, Literature, and the Ways to Culture, 1800-1918. Oxford: Clarendon Press.

Calvi, Maria Vittoria

2000 Il linguaggio spagnolo del turismo. Viareggio-Lucca: Mauro Baroni.

Calvi, Maria Vittoria

2006 Lengua y comunicación en el español del turismo. Madrid: Arco Libros.

Corominas, Joan / Pascual José A.

1980-1991 Diccionario crítico etimológico castellano e hispánico [DCECH]. Madrid: Gredos.

Enzensberger, Hans Magnus

1998 "Una teoria del turismo". En Questioni di dettaglio (pp. 24-48). Roma, Edizioni e/o. 
Fernández Cifuentes, Luis

1991 "Los viajes de Alarcón”. Ínsula, 535: 16-17.

Hernández Latas, José Antonio

2011 "De Madrid a Nápoles: Alarcón en la tertulia española del Café Greco y en el gabinete fotográfico de Altobelli y Molins". En Yeves Andrés, Juan Antonio (Ed.), Una imagen para la memoria. La carte de visite. Colección de Pedro Antonio de Alarcón (pp. 89-97). Madrid: Fundación Lázaro Galdiano.

Liberatori, Filomena

1981 I tempi e le opere di Pedro Antonio de Alarcón. Napoli: Istituto Universitario Orientale.

López, Ignacio Javier

2008 Pedro Antonio de Alarcón (prensa, politica, novela de tesis). Madrid: Ediciones de la Torre.

López, Lucio Vicente

1915 Recuerdos de viaje. Buenos Aires: L.J. Rosso y Cía.

Llamazares, Julio

1998 Trás-os-Montes. Madrid: Alfaguara.

MacCannell, Dean

2005 Il turista. Una nuova teoria della classe agiata. Torino: UTET.

Magris, Claudio

2005 L’infinito viaggiare. Milano: Mondadori.

Martínez Kleiser, Luis

1943 D. Pedro Antonio de Alarcón. Un viaje por el interior de su alma y a lo largo de su vida. Madrid: Librería General de Victoriano Suárez.

Montesinos, José F.

1977 Pedro Antonio de Alarcón. Madrid: Castalia.

Muñoz Viñé, María Luisa

1958 "Roma nel 1860 nelle impressioni di un grande scrittore spagnolo: P. A. de Alarcón”. L’Urbe, XXI: 7-14.

Pardo Bazán, Emilia

[s.a.] Alarcón. Estudio biográfico. Madrid: Hermanos Sáenz de Jubera.

Pardo Canalís, Enrique

1991 Pedro Antonio de Alarcón y Europa. Madrid: Instituto de Estudios Madrileños (CSIC) y Ayuntamiento de Madrid.

Pera, Cristóbal

1998 "De viajeros y turistas: Reflexiones sobre el turismo en la literatura hispanoamericana". Revista Iberoamericana, 64 (184-185): 507-528.

Romano, Julio [seud. de Hipólito Rodríguez de la Peña]

1933 Pedro Antonio de Alarcón. El novelista romántico. Madrid: Espasa-Calpe.

Walker, Adam

1792 Remarks Made in a Tour from London to the Lakes of Westmoreland and Cumberland. London: G. Nicol.

\section{Notas}

1 A quien desee profundizar en esta y sucesivas documentaciones en lengua inglesa, remitimos a Buzard (2011: 1).

2 La consulta de CORDE [en fecha de 24 de octubre de 2011] arroja el siguiente inventario de autores decimonónicos: Juan
Valera, Francisco Carrasco y Guisasola, Lucio Vicente López, Emilia Pardo Bazán y José María de Pereda. A ellos cabe añadir los que emplean el galicismo touriste (Pedro Antonio de Alarcón, Gustavo Adolfo Bécquer, Lucio Vicente López, Adolfo de Castro, Luis Coloma y Juan Valera) y el anglicismo tourist (Lucio Victorio Mansilla).

3 La fuente es el mismo autor: "A cincuenta mil ejemplares llegó la tirada hecha en Madrid por las prensas de mis buenos amigos los Sres. Gaspar y Roig (hoy difuntos); y como el precio medio de cada ejemplar ascendió a cincuenta reales, resulta que la obra produjo dos millones y medio. Es decir, que, deducidos gastos de impresión, y aunque aquellos señores se portaron conmigo espléndidamente (pues que, motu proprio me dieron doble cantidad de la contratada), el beneficio líquido del negocio pasó, para ellos, de noventa mil duros" (1943: 14). V.q. Martínez Kleiser (1943: 53-54).

4 También Julio Romano insistirá en este aspecto: "Los viajes, para un observador tan agudo y sagaz como Alarcón, eran espléndidas cacerías visuales" (1933: 131).

5 En el último cuarto de siglo registramos la publicación de las siguientes obras: Emilio Castelar, Recuerdos de Italia (1872 y 1876); José de Lasa, De Madrid al Vesubio (1873); Benito Pérez Galdós, Viaje a Italia (1888); Vicente Blasco Ibáñez, En el país del arte. Tres meses en Italia, (1896); Gregorio Iribas y Sánchez, Viaje por Italia y Suiza, pasando por el mediodia de Francia (1897).

6 No oculta este trasvase crudo, sino que lo explicita al lector. Apunta lamentando la falta de luz por la llegada de la noche: "no puedo descifrar la última línea que escribí o quise escribir a tientas en esa hoja de mi cartera de viaje» (1861: 122).

7 A la que se refiere en cierta ocasión como la Guía del viajero en Suiza (Alarcón, 1861: 123). Es en realidad, tal como hemos constatado, la versión francesa que lleva por título; La Suïsse, les lacs italiens, Milan, Turin, Gênes et Nice. Manuel du voyageur, Bædeker, Coblenz, 1859 ( $4^{\mathrm{a}}$ edic.).

8 Remitimos a Hernández Latas (2011) para más noticias sobre los contertulios habituales en el célebre establecimiento romano.

9 Las variantes y omisiones obedecen a otro tipo de causas, tal como señala Liberatori (1981: 66): "ha eliminato alcuni brani romanzeschi che ben difficilmente sarebbero stati accettati da un lettore di fine secolo; in altri casi, al contrario, i cambiamenti riguardano impressioni personali su fatti politici che avrebbero resa ancora più difficile la sua posizione».

10 Fernández Cifuentes incurre en distracción al afirmar que se registra tan solo una vez el galicismo en el conjunto de la obra del escritor de Guadix: "En sus cuatro libros de viajes (que ocupan casi el doble de páginas que sus novelas, y bastante 
más del triple que sus libros de cuentos o de 'otros escritos'), Alarcón solo utiliza una vez la palabra turista. Lo hace todavía en francés y en cursiva, pero ya en plural - touristes - como si previera la equivalencia de turismo y multitud" (1991: 16).

11 Tales divagaciones se suprimieron a partir de la segunda edición, que se publicó en 1878.

12 Estas turistas a las que en otro lugar aludirá, de modo burlesco, con el epíteto de fashionabilísimas inglesas (1861: 464). 